NASA Technical Memorandum 107102

IEPC-95-133

\title{
The NASA Electric Propulsion Program
}

\author{
Francis M. Curran \\ Lewis Research Center \\ Cleveland, Ohio \\ and \\ Lisa Wood Callahan \\ NASA Headquarters \\ Washington, D.C.
}

Prepared for the

24th International Electric Propulsion Conference

sponsored by the American Institute of Aeronautics and Astronautics

Moscow, Russia, September 19-23, 1995

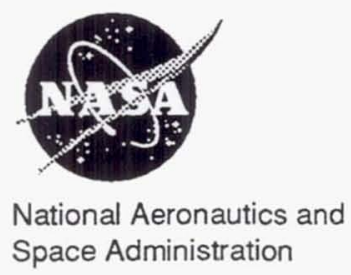




\title{
THE NASA ELECTRIC PROPULSION PROGRAM
}

\author{
Francis M. Curran \\ NASA Lewis Research Center \\ Cleveland, $\mathrm{OH} 44135$
}

\author{
Lisa Wood Callahan \\ Office of Space Access and Technology \\ Washington, D. C. 20546
}

\begin{abstract}
Nearly all space missions require on-board propulsion systems and these systems typically have a major impact on spacecraft mass and cost. Electric propulsion systems offer major performance advantages over conventional chemical systems for many mission functions and the NASA Office of Space Access and Technology (OSAT) supports an extensive effort to develop the technology for high-performance, on-board electric propulsion system options to enhance and enable near- and far-term US space missions. This program includes research and development efforts on electrothermal, electrostatic, and electromagnetic propulsion system technologies to cover a wide range of potential applications. To maximize expectations of technology transfer, the program emphasizes strong interaction with the user community through a variety of cooperative and contracted approaches. This paper provides an overview of the OSAT electric propulsion program with an emphasis on recent progress and future directions.
\end{abstract}

\section{INTRODUCTION}

The era of electric propulsion is now well under way. First generation arcjet systems have been in use for the north-south stationkeeping (NSSK) of the first Lockheed Martin Astro Space (LMAS) Series 7000 geosynchronous (GEO) communications satellite (comsat) for over a year and higher performance arcjets were recently accepted for a next generation comsat application (see Figure 1 and Ref. 1). In fact, every major GEO comsat manufacturer now offers an electric propulsion option (see, for example, Refs. 2, 3). Resistojets are now baselined for both the insertion of a distributed communications constellation and NSSK of next generation Air Force Defense Satellite Communications System (DSCS) spacecraft (Ref. 4). Ion propulsion was recently chosen for primary propulsion in the first flight in NASA's New Millennium program and other electric propulsion options (low power arcjets, pulsed plasma thrusters, and Hall thrusters) are being considered for several other missions. This interest in electric propulsion stems from the tremendous pressure now being exerted to assure cost-effective mission performance both in commercial and government sectors. As shown in Figure 2, on-board propulsion systems are dominant mass drivers in many mission scenarios and electric propulsion systems can provide large mass savings over state-of-practice (SOP) chemical systems. The potential leverage of electric propulsion was well illustrated in the first arcjet application. Here, propellant savings were used to reduce launch vehicle requirements and create an international launch vehicle competition. In the DSCS application, resistojets will be used to significantly extend GEO satellite life. The GEO market is expected to remain strong over the next decade (Ref. 5) and competition in this arena will drive technology development. Current trends are toward increased power levels and, with increased power, electric propulsion systems are expected to provide primary propulsion functions in addition to the traditional NSSK role. Advancement in this direction will be evolutionary, with electric propulsion used first to improve mission performance through apogee topping. Recent analyses show that use of electric propulsion systems for a portion of the orbital insertion can increase net spacecraft mass by 20 to 45 percent depending on available power and allowable trip times (see Figure 3 and Ref. 6). Higher performance electric power and propulsion systems (high specific impulse, greatly reduced specific mass) will allow the consideration of full electric orbit transfers. The Department of Defense also has strong interest in the use of electric propulsion for GEO repositioning (Ref. 4, 7). As noted above, resistojets will be used in the near term to deploy and maintain a distributed comsat system and other electric propulsion options are currently being examined for this relatively power rich (>1 kW) application class.

The general trend toward small spacecraft will also drive the development and implementation of electric propulsion technologies for both Earth orbit and planetary missions. Primary electric propulsion has often been proposed for high delta- $V$ planetary-class missions. Benefits include reduced launch mass requirements, reduced trip times, extended stays in rendezvous missions, and relaxed time window constraints. Kakuda, Sercel, and Lee (Ref. 8) recently showed that high performance ion propulsion systems could deliver substantial payloads to small bodies such as the asteroids Vesta or Ceres or the comet Kopff in a 
cost effective fashion using small spacecraft. Electric propulsion can also greatly enhance missions involving small, low power satellites in low and mid-Earth orbits (LEO/MEO). One example of this is the Total Ozone Mapping Spectrometer (TOMS) scheduled for launch in the near future on a Pegasus XL launch vehicle. The TOMS spacecraft will use a SOP hydrazine system for onboard propulsion functions. A deorbit system was not required at the time TOMS was designed. A recent analysis by Myers, Oleson, and Curran (Ref. 9) showed that TOMS-class missions could be significantly enhanced through the use of advanced pulsed plasma thruster technology. Results are shown in Figure 4 for both the TOMS mission as designed and with the addition of the deorbit requirement that would be imposed in today's environment.

A general trend toward the use of electric propulsion, shown in Table 1, is expected and an anticipated applications roadmap is shown in Figure 5.

NASA's Office of Space Access and Technology (OSAT) recognizes the benefits of electric propulsion and supports a strong electric propulsion element as part of its On-Board Propulsion (OBP) program. This electric propulsion program is designed to assure the availability of high performance electric systems for both near and far term missions. Program scope includes fundamental research, specific technology developments, and efforts aimed at technology transfer. OSAT also recognizes the synergism between advanced electric propulsion and power systems and has developed an integrated On-Board Power and Propulsion Strategy (Refs. 10,11 ) to ensure the simultaneous advancement of these two critical technologies. This strategy assumes that the needs for higher performance propulsion and power systems will increase over the next decade and that there will be a general trend toward the use of small spacecraft. OSAT works in cooperation with industry and other government progams to bring critical technologies to levels required for customer acceptance. Direct interactions with the user community and the development of commercial sources for program-sponsored technologies are strongly emphasized. OSAT also supports a focused NASA Solar Electric Propulsion Technology Application and Readiness (NSTAR) program, led by the Jet Propulsion Laboratory in partnership with NASA's Lewis Research Center, to develop and demonstrate a $0.5-2.5 \mathrm{~kW}, 55 \%$ efficient ion system (Isp $3100 \mathrm{sec}$ ) that will enable launch vehicle class reductions as well as significant trip time savings for small satellite planetary missions. NSTAR was initiated in FY93 and has baselined $30-\mathrm{cm}$ ion engine technology developed under the OBP program. As noted above, ion propulsion (the NSTAR system) has been chosen for the first flight in NASA's New Millennium program. This paper provides an overview of the electric propulsion element of the OBP program.

\section{NASA EP PROGRAM DESCRIPTION}

High performance electric propulsion technologies will be required to meet the stringent performance goals for missions such as those discussed above. OBP program objectives are to identify, develop, and transfer high performance propulsion technologies for both near ( $3-5$ year) and far ( 5 10 year) term missions. Both electric and chemical elements are included to cover the broad range of mission requirements (Ref. 12). The electric propulsion element includes efforts in each of the three major electric thruster classes (i.e. electrothermal, electrostatic, and electromagnetic). Many of these technologies cross cut several missions and every effort is made to assure that the sponsored technologies are capable of performing multiple missions.

\section{Electrothermal Systems}

The OBP arcjet program was recently reviewed in detail (Ref. 13). Following the transfer of first generation arcjets, a 600 second, $2 \mathrm{~kW}$-class arcjet system development program was undertaken with the Olin Aerospace Company (OAC) in response to a known user needs (GEO NSSK) and to provide technology for anticipated LEO/MEO satellite insertion and deorbit requirements. The OBP effort recently culminated in a successful qualification-level life test of a flight-type hardware. With commercial acceptance of 600 second arcjet technology, the OBP program is now focused on low power arcjets (LPATs) for power-limited spacecraft. Over the past year, sub-kW arcjet systems have been considered for application to LEO/MEO orbit insertion, NSSK of power limited military GEO comsats, and for space science missions like the Near Earth Asteroid Rendezvous and Sample Return mission. At this time, both a commercial technology demonstration spacecraft and a military application are potential first insertion targets for LPATs and the program will demonstrate flight-type $(0.5 \mathrm{~kW}, 450-500$ second Isp) hardware in the 1996/1997 timeframe. In addition to the LPATs program, the OBP program also sponsors feasibility research on $0.25 \mathrm{~kW}$-class device for very small spacecraft (Ref. 14) and is evaluating arcjet technology for advanced orbital insertions. 


\section{Electrostatic Systems}

Major electrostatic concepts include both gridded ion and Hall effect thrusters. As noted, gridded ion thruster technology previously sponsored by the OBP program is now the the subject of focused development. Currently, several cooperative programs to evaluate Hall thrusters for low power (sub-2 kW) applications are supported. Both higher power/performance Hall and next generation gridded ion technologies are being examined for future high delta- $\mathrm{V}$ missions. Over the next year, the OBP will also initiate an effort to evaluate the fundamental feasibility of a microelectrostatic system (sub-0.1 kW) for microspacecraft missions.

Hall thrusters have been extensively developed in Russia (Ref. 15) and have generated significant interest in the western aerospace community over the past several years. Two variations exist, the stationary plasma thruster (SPT) and the thruster with anode layer (TAL). Demonstrated performance characteristics are similar for both devices. For the $\mathrm{kW}$-class, demonstrated specific impulse for both devices is on the order of $1600 \mathrm{~s}$ at 0.50 efficiency. Both $0.7 \mathrm{~kW}$ and $1.5 \mathrm{~kW}$ SPT's made by Fakel Enterprises are operational on Russian satellites and the $1.5 \mathrm{~kW}$ version is now being readied for commercial use on western commercial GEO comsats (Ref. 2). Extended, cyclic life (>6000 hours/5000 cycles) was recently demonstrated for the $1.5 \mathrm{~kW}$ thruster (Ref. 16) and extensive evaluations of integration impacts have been undertaken including several large scale tests in OBP testbeds in cooperation with industry (see, for example, Ref. 17).

Over the past several years, the OBP program has acted as an agent for the Ballistic Missile Defense Organization's (BMDO) electric propulsion program. At present, this program is focused on the development of an advanced $1.5 \mathrm{~kW}$ Hall thruster system "on-a-pallet" in the Russian Hall Effect Thruster Test program (RHETT - see Refs. $18,19)$, and OBP personnel manage this effort. The first flight-like package (RHETT-1, shown in Figure 6) will be demonstrated in ground testing in 1995 and a follow on, flight-ready system (RHETT2 ) is planned for a near term flight test.

Sub-kW Hall thrusters are being considered for several missions including space science. One high potential mission prospect is the Energetic Transient Array (ETA) mission now being developed in a Phase A study by the Massachusetts Institute of Technology in NASA's MIDEX program. In ETA, eight small spacecraft would be distributed in heliocentric orbit to locate gamma ray sources as a follow on to the Gamma Ray Observatory. Existing SPT thrusters, built by Fakel and supplied by the Air Force Phillips Laboratory, are baselined for spacecraft insertions. The OBP program will provide support to the ETA program (under a Space Act Agreement) in the form of extensive propulsion system demonstrations in ETA's ground test element.

Sub-0.5 kW Hall thrusters may offer very high performance levels for power limited applications but have not yet been demonstrated. The OBP program is currently supporting development/evaluation of two low power Hall technologies. One of these, a $0.5 \mathrm{~kW}$-class TAL, was built by Russia's Central Research Institute of Machine Building (TsNIIMASH), through Texas Tech University, and will shortly be delivered for testing. Similarly, the Moscow Aviation Institute, through the Atlantic Research Corporation will provide a $0.25 \mathrm{~kW}$ SPT thruster. Both of these Hall thrusters are engineering models and will be evaluated (performance, life, and integration impacts) in 1995 and 1996. Further development efforts will hinge on the outcome of this research.

For the far term ( 5 to 10 years), the OBP program has initiated efforts to develop a very high efficiency ( $>0.6$ ), low-mass plasma propulsion system with end-to-end system specific mass (including power) and lifetime goals of $10 \mathrm{~kg} / \mathrm{kW}$ and 15,000 hours, respectively. These capabilities will enable three to five year trip times for complex space science missions with small spacecraft and high delta- $V$ orbit transfers with large payload fractions and relatively short trip times. At least two electrostatic concepts, an advanced gridded ion system and a high power (> $5 \mathrm{~kW}$ ) Hall thruster-based system, will be considered. For the gridded concept, several potential grid technology options will be explored. Carbon-carbon grid technology (see, for example, Ref. 20) developed under OSAT's Advanced Concepts Program has shown great promise for reducing grid erosion and this technology is currently being transitioned to the OBP program. Several promising coatings for conventional molybdenum grids are also being examined. Some initial evaluations of high power Hall technology have been initiated in conjuction with the BMDO program (see, for example, Ref. 21). Low-mass power systems for these advanced concepts will incorporate new high voltage array, power conversion, and power distribution technologies and efforts are underway, with the OSAT Space Power program, to demonstrate advanced power system concepts (Ref 22). 
Electromagnetic Systems

For many years the magnetoplasmadynamic thruster (MPD) was the major focus of OBP program efforts in the electromagnetic regime. Because of their large power handling capabilities and projected high performance, MPD systems were considered prime candidates for very ambitious, high power missions such as those proposed for the Space Exploration Initiative. The recent trend toward small satellites relegates MPD research to the back burner and the OBP program retains only a minor effort to examine the feasibility of MPD thrusters for dual use applications such as plasma processing/manufacturing. Pulsed plasma thrusters (PPT) are now the focus of the OBP electromagnetic element for several reasons. These devices utilize solid propellant and provide over $1000 \mathrm{~s}$ of specific impulse while operating at power levels between 2 and 60 watts. Because the systems are pulsed, power throttling can be easily accomplished without changing performance by varying repetition rate. Impulse bits at least three orders of magnitude below those available with hydrazine engines $(13 \mathrm{mN}-\mathrm{s})$ can be used to provide fine orbit control. The use of solid teflon propellant eliminates hazardous propellant storage and handling concerns and results in a very simple, low-cost feed system. These attributes make PPTs highly attractive for a range of small spacecraft applications (Ref. 23). The $\mathrm{OBP}$ program is now in the middle of a two phase PPT technology development effort which includes in-house, contracted, and university efforts. The first phase is focused on simultaneously reducing the PPT system mass by a factor of two and doubling total impulse capability in order to provide a four fold increase in propulsion system capability per unit launch mass as compared to SOP PPT systems. The second phase will further miniaturize the technology and fundamental research efforts toward this end are already in progress. In the contracted effort, the OAC will first develop a flight-type system for demonstration in 1997. The academic effort, conducted with the Ohio State University (OSU), is building on past code development efforts (MACH 2 - Ref. 24) to develop a high fidelity PPT model to be used in the design of next generation PPT's. Fundamental experimental research into design issues related to the further miniaturization of PPT technology is being performed in collaboration with the LeRC in-house program. OSU is also exploring new propellant options for increasing PPT performance without degrading life (Ref. 25). To date, layered polymer combinations that may provide higher average specific impulse characteristics but avoid electrode carbonization problems encountered in previous advanced fuel development efforts are being tested. All of the on-going PPT experimental efforts take advantage of existing OBP testbeds at LeRC. The LeRC inhouse program has several foci. In addition to the experimental effort with OSU to develop fundamental scaling information, the program also includes characterization of performance, EMI, and plume impacts. Recent accomplishments under the PPT effort include the development and demonstration of both a new power converter which will provide reductions in volume $(3 X)$, weight (2X), parts count (4X), and power consumption (3.5X) over SOP systems and a telemetry board providing a $4 X$ reductions in the same areas. Also, two candidate capacitor technologies with $4 X$ the SOP specific energy density have been identified and cyclic testing in progress using a test apparatus designed and delivered by a small disadvantaged business. Finally, a high precision thrust stand was developed and demonstrated (Ref. 26).

As a final note, the OBP program is working cooperatively with the Air Force and Weber State University in the joint Air Force/Webber State student satellite project (JAWSAT). JAWSAT will fly SOP LES $8 / 9$ PPT technology on a $50 \mathrm{~kg}$ educational smallsat which will use the Global Positioning System (GPS) for navigation. Under this program, OBP personnel are conducting and directing tests in LeRC space propulsion testbeds to quantify and address issues related to PPT/spacecraft integration as illustrated in Figure 7. Programs such as JAWSAT provide educational opportunities for students and OBP personnel alike and valuable information on spacecraft integration to be used in the development of next generation systems.

\section{CONCLUDING REMARKS}

Advanced electric propulsion systems will be needed to increase mission performance into the forseeable future. NASA's Office of Space Access and Technology (OSAT) sponsors an aggressive On-Board propulsion program designed to meet the needs of both near- and far-term missions. The OBP program includes a strong electric propulsion element. Synergistic space power technologies are addressed in a complementary OSAT program. The OBP program stress technology transfer. For this, program efforts are directed toward both the development of commercial technology sources and the demonstration of program technologies to the level required by potential users. OSAT's program is committed to providing cutting edge electric propulsion technologies to the aerospace 
community and invites interactions with the community to help meet this goal.

\section{REFERENCES}

1. Lichon, P. G. and Sankovic, J. M., "Development and Demonstration of a 600 Second Mission Average Arcjet," IEPC-93-087, September 1993.

2. Day, M., Maslennikov, N. A., and Rogers, W. P., "SPT-100 Subsystem Development Status and Plan," AIAA-94-2853, June 1994.

3. Beattie, J. R., Williams, J. D., and Robson, R. R., "Flight Qualification of an $18-\mathrm{mN}$ Xenon Ion Thruster," IEPC-93-106, September 1993.

4. Spores, R. A., et al., "The Air Force Electric Propulsion Program," AIAA-95-2378, July 1995.

5. U. S. Transportation Department, Office of Commercial Space Transportation, Commercial Space Transportation Advisory Committee 1995 GTO Projection.

6. Oleson, S. R., et al., "Advanced Propulsion for Geostationary Orbit Insertion and North-South Station Keeping," AIAA-95-2513, July 1995.

7. Riehl, J. P., Morales, N., and Oleson, S. R., "Benefits of Ion Electric Propulsion for Earth Orbital Applications," to be published as a NASA TM, 1995.

8. Kakuda, R., Sercel, J., and Lee, W., "Small Body Rendezvous Mission Using Solar Electric Propulsion: Low Cost Mission Approach and Technology Requirements," IAA-I-0710, April 1994.

9. Myers, R. M., Oleson, S. R., and Curran, F. M., "Small Satellite Propulsion Options," IECEC-944137, August 1994.

10. Callahan, L., et al., "On-Board Power and Propulsion Strategic Plan," NASA Office of Space Access and Technology, 1995.

11. Curran, F. M., Schreiber, J. G., and Callahan, L., "Electric Power and Propulsion: The Future," IECEC-95-366, August 1995.

12. Curran, F. M. and Callahan, L., "The NASA OnBoard Propulsion Program," AIAA-95-2379, July 1995.
13. Curran, F. M., and Byers, D. C., "New Developments and Research Findings: NASA Hydrazine Arcjets," AIAA-94-2463, June 1994.

14. Sankovic, J. M. and Jacobson, D. T., "Performance of a Miniaturized Arcjet," AIAA-952822, July 1995.

15. Barnett, J. W., "A Review of Soviet Plasma Engine Development," AIAA-90-2600, July 1990.

16. Garner, C., et al., "A 5,730- $\mathrm{Hr}$ Cyclic Endurance Test of the SPT-100," AIAA-95-2667, July 1995.

17. Randolf, T., and Pencil, E. J., "Far-Field Plume Contamination and Sputtering Characteristics of the Stationary Plasma Thruster," AIAA-95-2855, June 1994.

18. Allen, D. M., et al., "RHETT and SCARLET: Synergistic Power and Propulsion Technologies," AlAA-95-368, August 1995.

19. Caveny, L. H., "The BMDO Electric Propulsion Flight Readiness Program," IEPC-95-132, September 1995.

20. Mueller, J., Brophy, J. R., and Brown, D. K., "Endurance Testing and Fabrication of Advanced $15-\mathrm{cm}$ and $30-\mathrm{cm}$ Carbon-Carbon Composite Grids," AIAA-95-2660.

21. Sankovic, J. M., Haag, T. W., and Manzella, D. $\mathrm{H}$., "Performance Evaluation of a $4.5 \mathrm{KW}$ SPT Thruster," IEPC-95-30, September 1995.

22. Hamley, J. A., Direct Drive Options for Electric Propulsion Systems," AIAA-95-346, July-August 1995.

23. Myers, R. M., et al., "Pulsed Plasma Thruster Technology for Small Satellite Missions," Presented at the 9th Annual AIAA/USU Small Satellite Conference, Logan, UT, September 1995.

24. Turchi, P., "Modeling of Ablation-Fed Pulsed Plasma Thrusters," AIAA-95-2915, July 1995.

25. Leiwike, R., Myers, R. M., and Turchi, P., "Multimaterial Propellants in Ablation-Fed Pulsed Plasma Thrusters," AIAA-95-2916, July 1995.

26. Haag, T. W., "PPT Thrust Stand," AIAA-952917," July 1995. 
Table 1. Anticipated On-Board Propulsion Trends.

\begin{tabular}{|c|c|c|c|}
\hline FUNCTION & LEO/MEO & GEO & SPACE SCIENCE \\
\hline - INSERTION & - $\rightarrow \mathrm{O}$ & - $\rightarrow \mathrm{O}$ & - $\rightarrow$ Oי \\
\hline - ORBIT CONTROL & r $\rightarrow$ o & $\bullet \rightarrow \mathrm{O}$ & $\rightarrow$ \\
\hline - REPOSITIONING & - $\rightarrow \mathrm{D}$ & - $\rightarrow \square$ & $\rightarrow \square$ \\
\hline - DEORBIT & $\rightarrow$ O & N/A & N/A \\
\hline - SAMPLE/RETURN & N/A & N/A & $\rightarrow$ \\
\hline
\end{tabular}

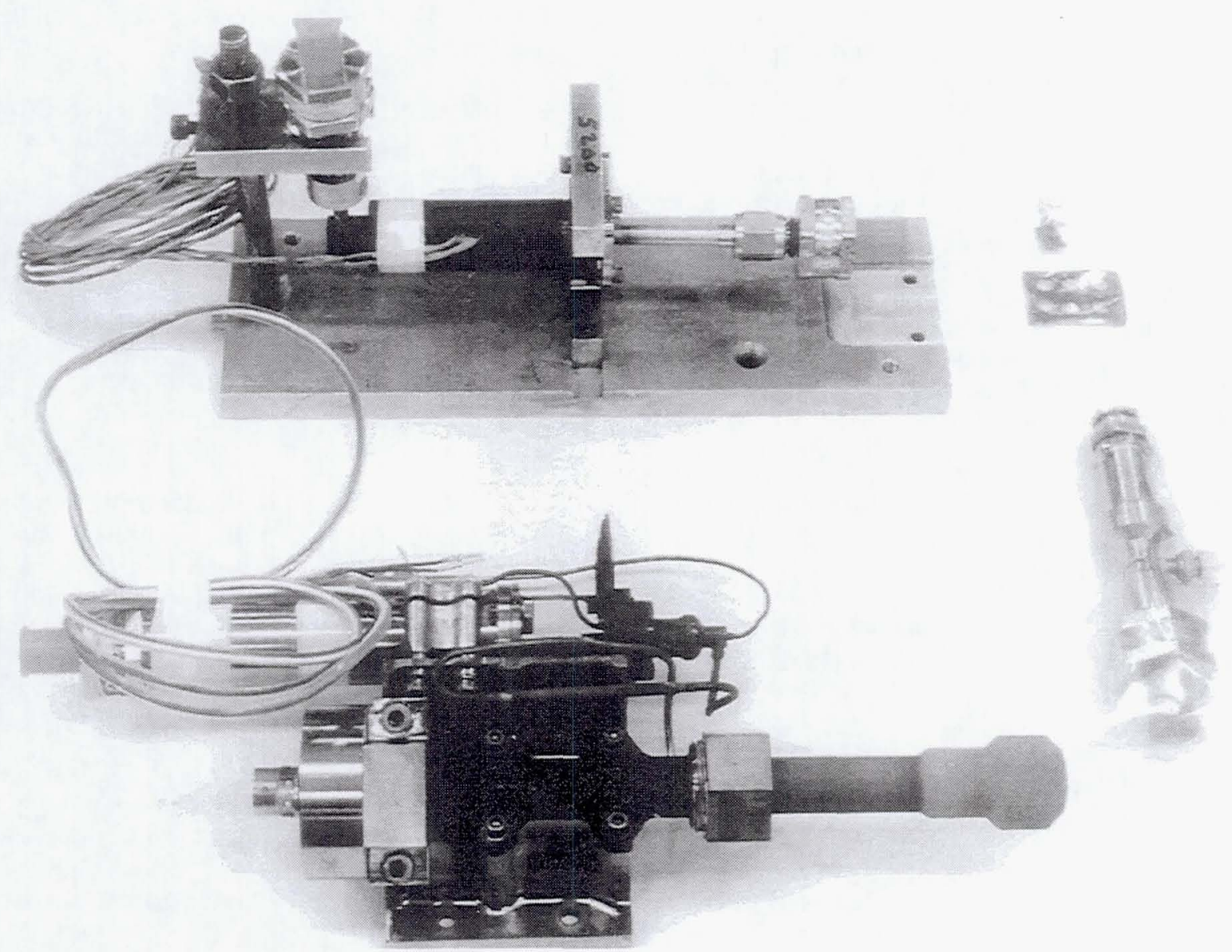

Figure 1. High performance (600 s Isp) arcjets for next generation communications satellites. 


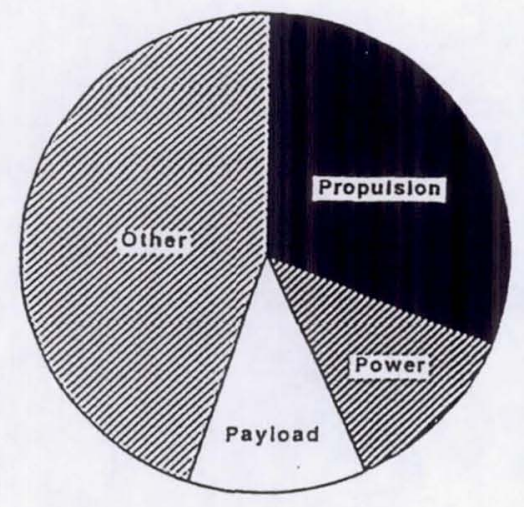

EARTH SCIENCE

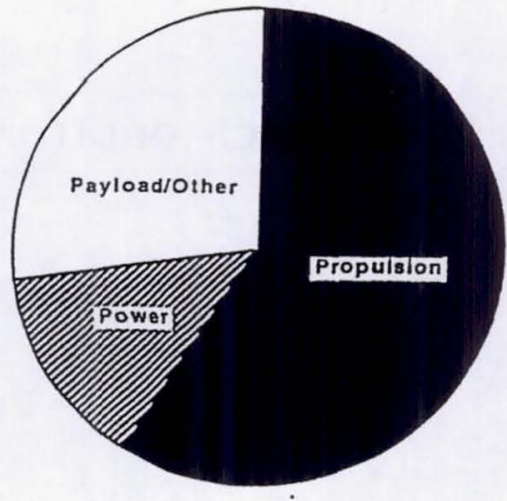

GEO COMSAT

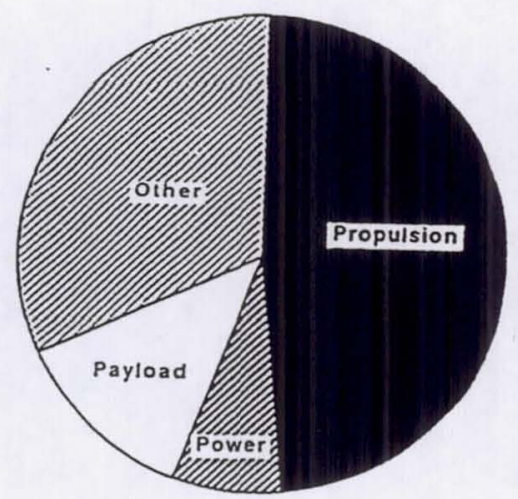

PLANETARY

Figure 2. Spacecraft wet mass fractions for Earth-orbit and planetary missions.

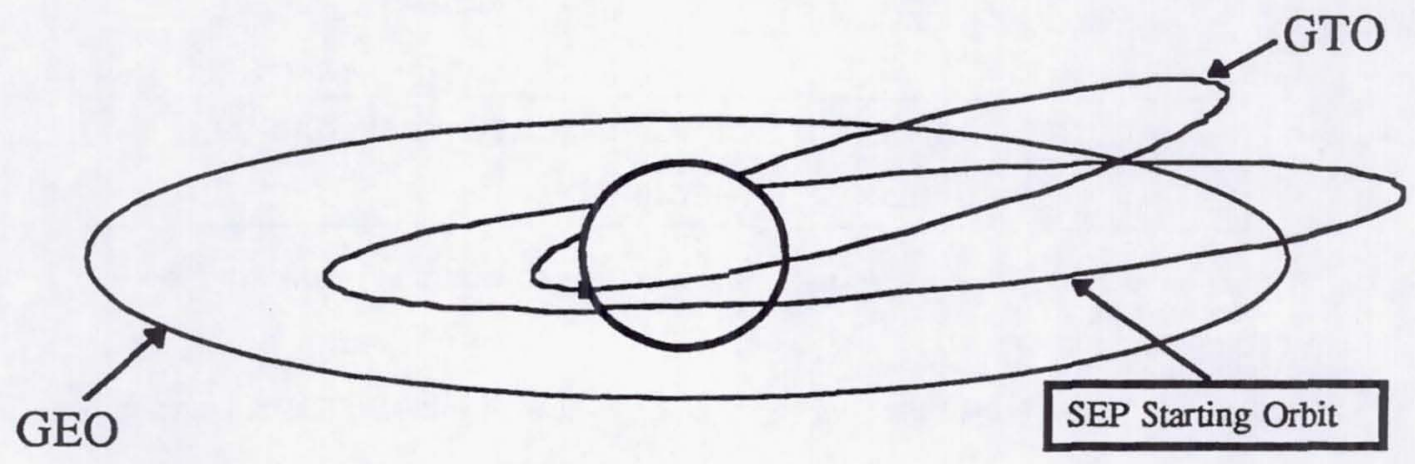

a) Near-term electric propulsion orbit insertion strategy for GEO comsats.

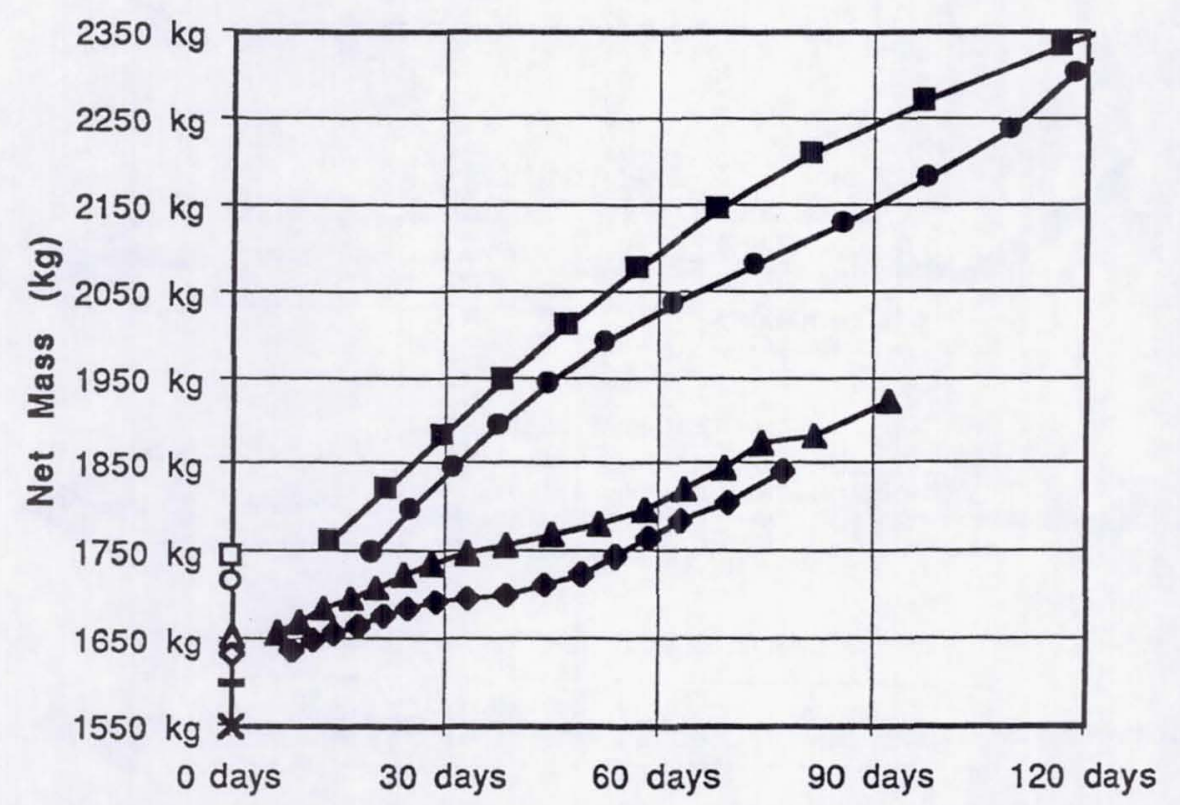

\begin{tabular}{|ll|}
- & - Ion,15kW \\
$\square$ & lon NSSK \\
- & Xe-Hall,15kW \\
0 & Xe-Hall NSSK \\
- & N2H4-AJ+,15kW \\
$\Delta$ & N2H4-AJ+ NSSK \\
- N2H4-AJ,15kW \\
$-\quad$ N2H4-AJ NSSK \\
$-\quad$ Adv Chem/ AJ SOA \\
$\times \quad$ Chem/AJ SOA \\
\hline
\end{tabular}

b) Final net mass versus transfer time for a $15 \mathrm{~kW}$-class GEO comsat with various electric propulsion options for part of the orbit insertion function.

Figure 3. Advanced cemical/electric orbit transfer strategy and payoffs (from Ref. 6). 


\section{SUN-SYNCH ORBIT INSERTION ${ }^{(1)}$}

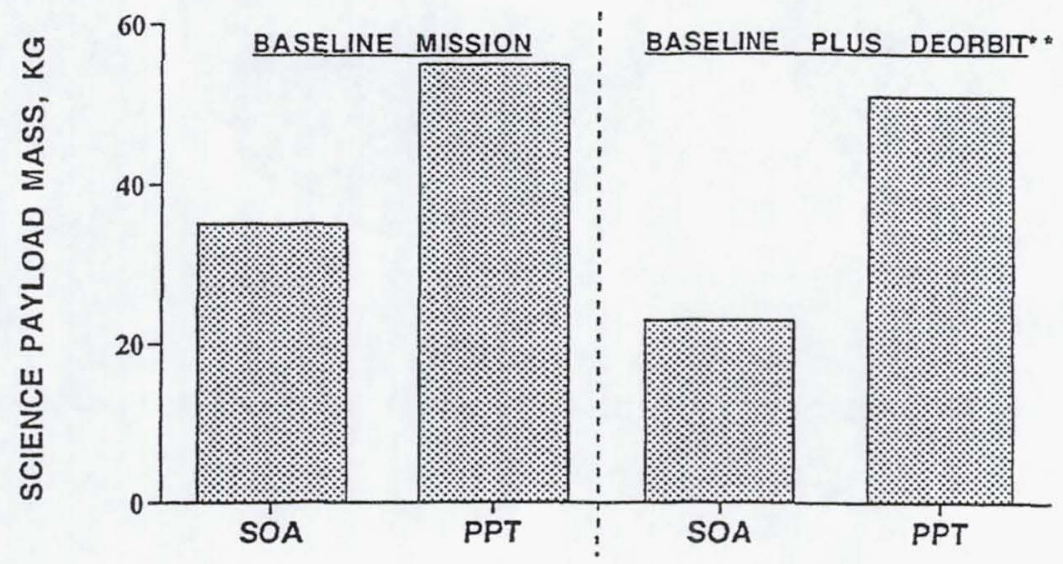

\section{ELECTRIC PROPULSION INCREASES TOMS-EP PAYLOAD BY: - $57 \%$ IN BASELINE MISSION $-122 \%$ IF DEORBIT IS REQUIRED}

(1)

TOMS-EP MISSION, LAUNCH MASS OF $287 \mathrm{KG}$, FINAL ORBIT ALTITUDE OF $955 \mathrm{KM}$, 80 DAY INSERTION

* DEORBIT TO $500 \mathrm{KM}$.

Figure 4. Electric propulsion benefits for an Earth science mission (TOMS example).

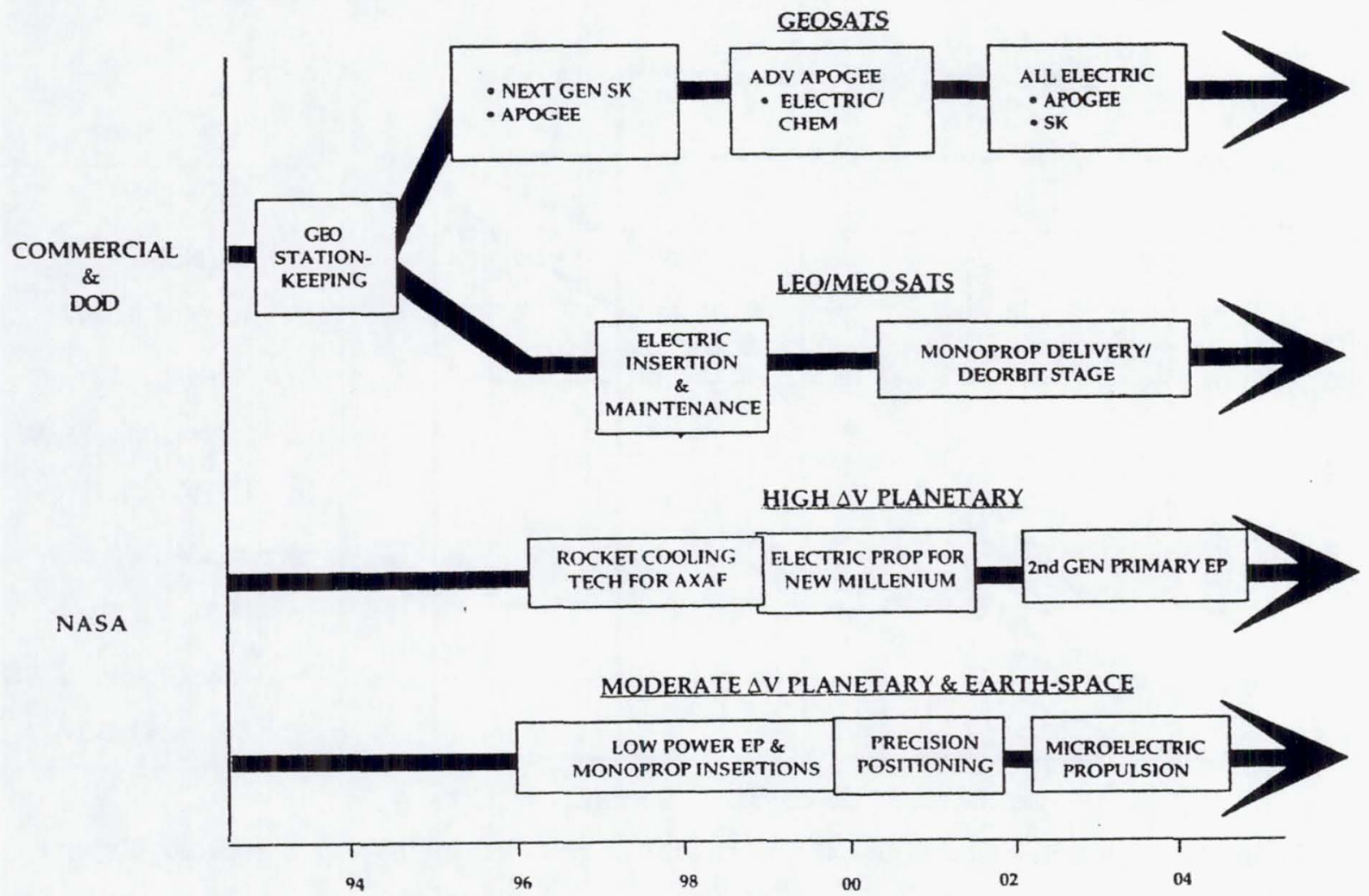

Figure 5. On-board propulsion applications roadmap. 


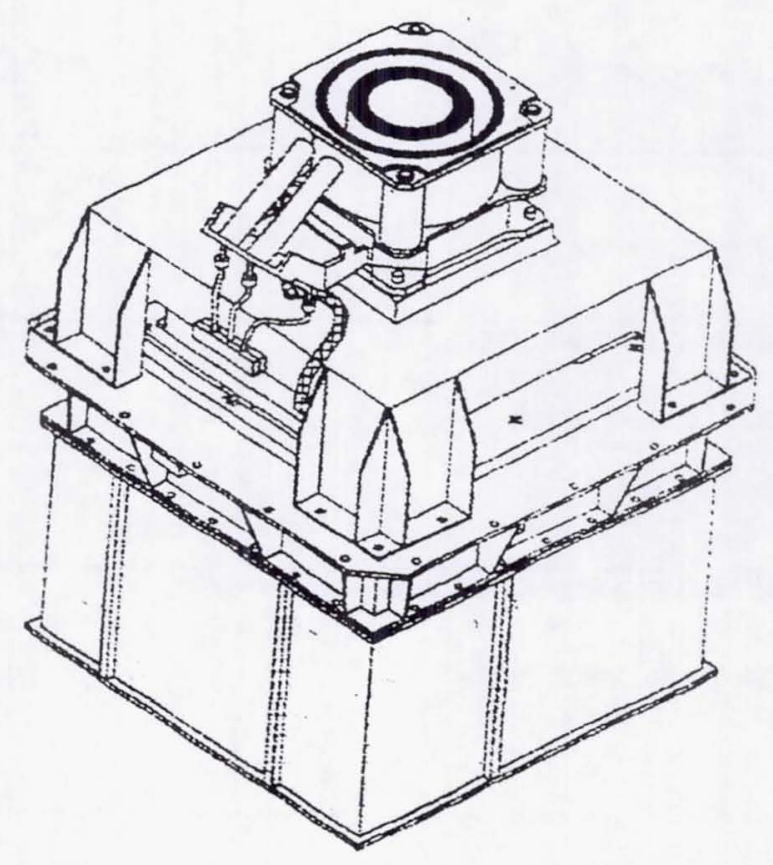

Figure 6. RHETT-1 demonstration package.

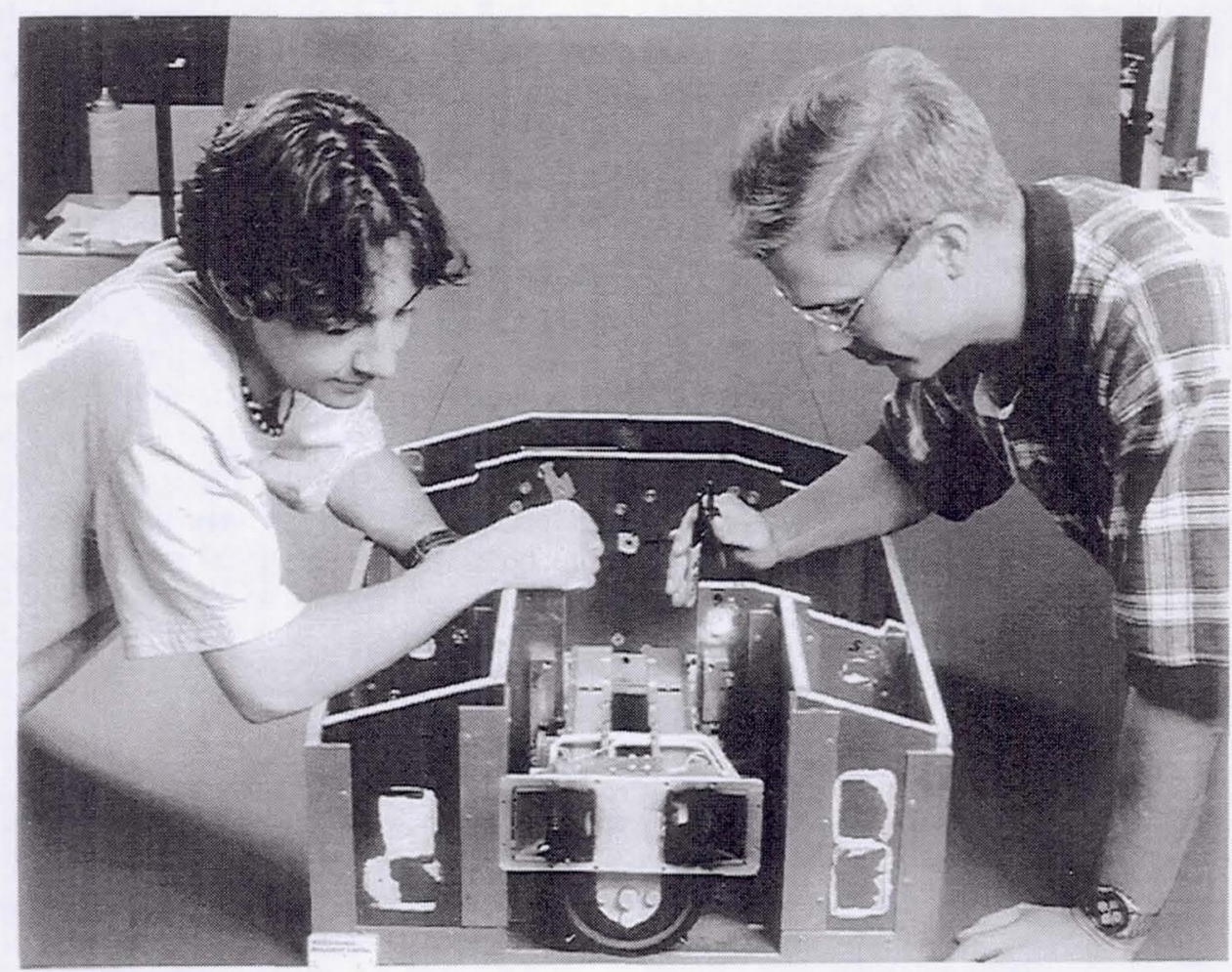

Figure 7. Students preparing JAWSAT for PPT integration impacts testing. 


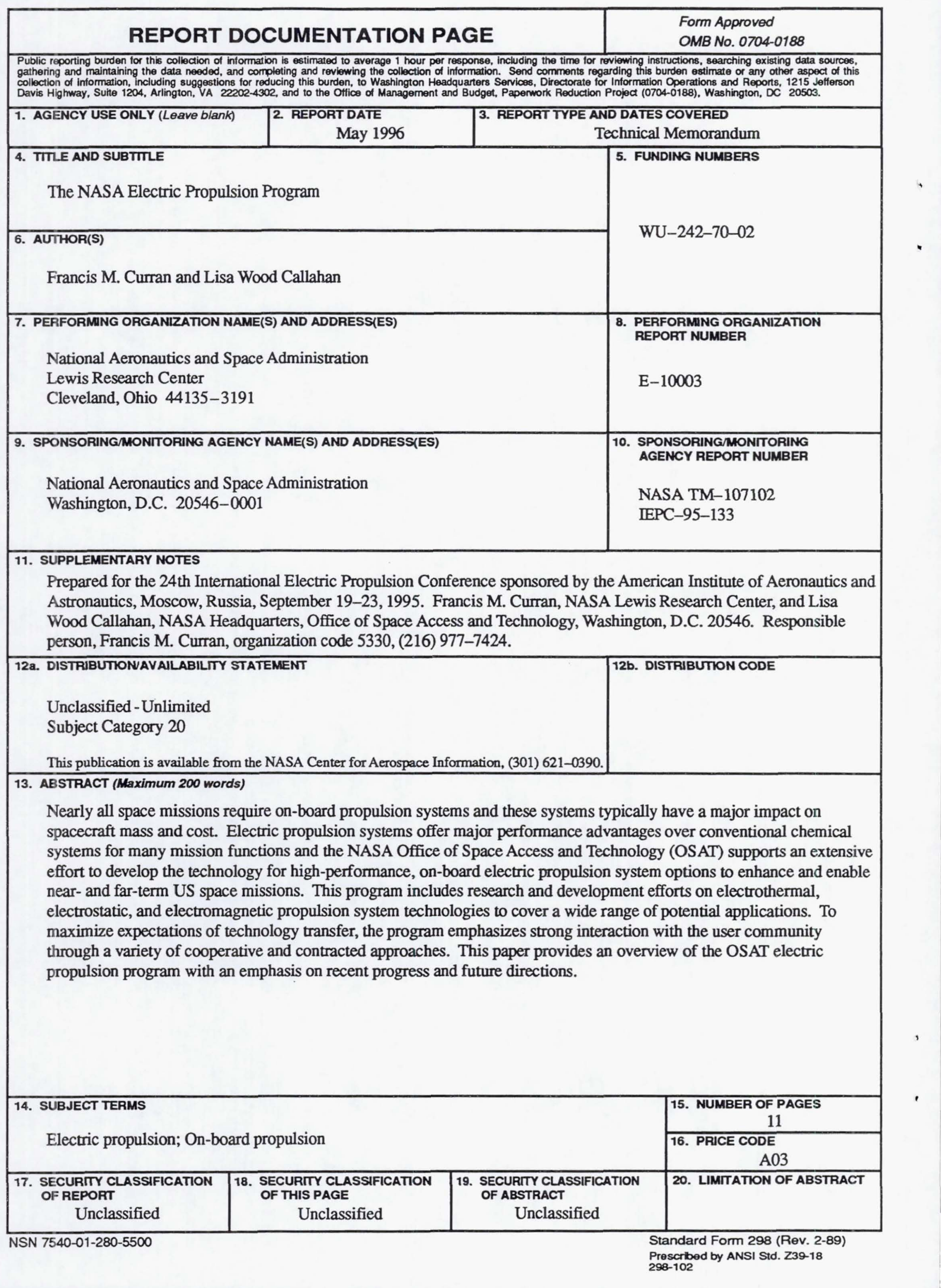

